East African Medical Journal Vol. 81 No. 2 February 2004

NON-SURGICAL MANAGEMENT OF A CHRONIC PERIAPICAL LESION ASSOCIATED WITH TRAUMATISED MAXILLARY CENTRAL INCISORS: CASE REPORT

G. C. Ogonji, BDS, MScD, Division of Dental Services, Ministry of Health, Afya House, P.O. Box 30016, Nairobi, Kenya

\title{
NON-SURGICAL MANAGEMENT OF A CHRONIC PERIAPICAL LESION ASSOCIATED WITH TRAUMATISED MAXILLARY CENTRAL INCISORS: CASE REPORT
}

\author{
G. C. OGONJI
}

\begin{abstract}
SUMMARY
A case is reported of a chronic periapical lesion involving maxillary central incisors with a history of traumatic injury eight years previously and subsequent development of a painful swelling that occasionally caused partial blockage of the nasal cavities. Retrograde surgery for removal of the suspected cystic lesion was scheduled. As a temporary measure before surgery, the necrotic pulp exudate was removed through standard endodontic access cavities prepared on the palatal surfaces of the crowns of the two central incisors, and a calcium hydroxide paste dressing material was placed inside the root canals up to the apices. The calcium hydroxide dressing was changed every four weeks and the case was followed up until healing of the periapical lesion occurred. The surgical procedure was postponed and finally cancelled when complete healing became evident in recall radiographs.
\end{abstract}

\section{INTRODUCTION}

Usually when trauma or dental caries causes a tooth to lose its vitality, the pulp cavity and canals become repositories for a necrotic pulp tissue. This degenerating tissue (with or without bacteria) produces periapical irritation through the apical foramina(1,2). The body attempts to combat this irritation by an inflammatory response. If a virile organism is responsible for the infection, the process is likely to be acute. On the other hand, if the organism is not virile or if the irritation is produced by toxins of the necrotic pulp, the process is likely to be chronic(2).

Treatment of an anterior tooth with chronic periapical infection will depend on the clinical situation. If the tooth is firm and has sound periodontal tissue support, conventional endodontic treatment should be carried out. However, in situations of persistent periapical infection despite initial endodontic treatment, apicectomy is indicated, particularly in adolescents and adults. Generally, if the clinical outcome by all treatment modalities is considered doubtful, then extraction may be resorted to $(4,5)$.

The purpose of this case study was to demonstrate the need for conservative endodontic management of chronic periapical infections involving anterior permanent teeth in children and young adults as a first line approach in well-defined case selections. The study further emphasises the importance of interdisciplinary consultations to broaden knowledge and clinical skills in patient management.

\section{CASE REPORT}

A twenty year old man was referred to the Department of Dentistry at Kenyatta National Hospital for evaluation and management of pain associated with his maxillary central incisors, a swollen upper lip and recurrent blockage of the nostrils. Medical history revealed a previous visit to an Ear, Nose and Throat (E.N.T) surgeon who initially put him on a seven day course of suitable antibiotics and anti-inflammatory drugs orally, pending a surgical intervention to enucleate what appeared to be an infected cyst (Figure 1). Further enquiry showed that eight years previously the patient had an accidental fall off his bicycle that caused exarticulation of his maxillary central incisors. These teeth were then immediately reimplanted into their respective sockets and firmly held in place under digital pressure for about one hour by the patient's mother.

No medicaments were administered apart from the use of basic analgesics and warm salt water gargle daily for the relief of pain and for prevention and control of bad breath. The patient claimed to have been fine till he noticed discolouration of the affected teeth followed by pain and swelling in the anterior maxillary alveolar bone, the upper lip and nasal cavities, giving rise to difficulty with breathing and biting.

On examination he was found to be in relatively good health except for his poor oral hygiene. His maxillary central incisors which appeared discoloured with a yellowish tinge, were tender and slightly mobile labio-palatally. In the labial sulcus, periapically, a soft tender swelling was evident. The swelling extended to the upper lip as well as to the palate, and appeared to have superiorly displaced the floor of the nasal cavities. There was no reaction to electric pulp vitality test.

Intraoral radiographs revealed a diffuse area of bone rare faction involving the apices of maxillary central incisors (Figure 1). A purulent discharge draining from the periapical area through the root canals and access cavities prepared on the two central incisor crowns was cultured for its microbial content and drug sensitivity(1). The culture revealed a growth of alpha streptococci and staphylococci with a strong sensitivity to Amoxycillin and a combination of Ampicillin and Cloxacillin. Based on these findings, a course of Ampiclox capsules 500mg six hourly and metronidazole tablets $400 \mathrm{mg}$ eight hourly as well as anti-inflammatory drugs were administered for five days. Meanwhile the prepared access cavities were left open to facilitate drainage of the abscess from the periapical region. 
Debridement of the root canals, to eliminate infection and to wash out the debris that might have accumulated during the period of open drainage, was then started using conventional endodontic biomechanical preparation and thoroughly irrigating alternately with $2 \%$ hydrogen peroxide and 5\% sodium hypochlorite solutions $(1,3,8)$. Formocresol solution on cotton pledgets was the dressing material of choice for the prepared canals during the first two visits at weekly intervals owing to its strong germicidal properties(6), especially in destroying the Streptococci and Staphylococcus aureus in dentine $(1,3)$. However, as it is also an irritant to periapical tissues $(1,4)$ the use of formocresol was discontinued after the two visits and subsequently replaced by a calcium hydroxide paste(7,10-13) which was carried into the canals using a syringe fitted with a suitable tip. This dressing material was held in place by cotton pledges in the pulp chambers and a temporary restorative cement. For the first three months, the dressing material was changed every four weeks and thereafter every six weeks until repair of the periapical bone was evident(Figure 2).

\section{Figure 1}

Chronic alveolar abscess of upper permanent central incisors upon presentation of the patient for endodontic treatment

\section{Figure 2}

Condition eight weeks after dressing with calcium hydroxide paste. Initial periapical tissue healing is evident
Figure 3

Fourteen months dressing with calcium hydroxide paste, periapical tissue healing is nearly complete and root canals are subsequently filled with gutta percha points

\section{Figure 4}

Six months after obturation with gutta percha points. Complete periapical tissue healing is evident

Healing progressed slowly but uneventfully over the following ten months. At a recall appointment fourteen months after his initial presentation, the patient appeared generally well with no evidence of a recurrence of periapical infection or periodontitis. This observation was confirmed by the minimal presence of periapical exudate in the root canals: absorbent paper points inserted into the canals up to the apices became moist with fluid which yielded negative bacterial culture. Follow up radiographs showed complete repair of the periapical connective tissues.

The encouraging results from the review appointments pointed to the readiness of the two teeth for obturation. After the root canal walls and apices were well coated with a suitable root canal cement sealer (Tubli-seal®) appropriate sized gutta percha master cones were also coated with the cement along their apical half and introduced into the canals to obturate them to the predetermined levels using the lateral condensation technique with smaller gutta percha points. The excess 
cement and gutta percha material in the pulp chamber were removed and replaced with an intracoronal seal of glass ionomer cement (Figures 3 and 4).

\section{DISCUSSION}

This is perhaps the first documented case in Kenya of a chronic periapical lesion involving the anterior teeth in the maxilla that has, in its management, attracted the interest of an E.N.T surgeon and dental colleagues. A non-surgical approach was at first considered as a temporary measure prior to a planned retrograde surgery for the removal of a periapical cystic lesion. It was argued that in the event of this method failing to produce the desired results, surgery would have been resorted to despite its shortcomings and traumatic effects.

In this particular non-surgical technique, calcium hydroxide paste was considered and used as the intracanal dressing material of choice because of its reputed healing of periapical inflammation and formation of an apical hard tissue barrier(3,7,10-13). The influence of calcium hydroxide on periapical healing could be attributed to both its antibacterial effects and mineralising effects. Micro-organisms coming in direct contact with calcium hydroxide are possibly destroyed by its high alkalinity (usually $\mathrm{pH} 12$ to 13). Once the bacteria are destroyed and their substrate neutralised, the calcium hydroxide in contact with vital connective tissue in the apical area exerts basically the same effect as when it is placed on the coronal pulp(5,8,10-15). Tissue layers similar to those formed after pulpotomy and pulp capping with calcium hydroxide have been noted in the apical barrier. But instead of reparative dentine, a collagenous cementum-like tissue is formed, probably because different cells are involved(4,6-8,13-14). A twoyear follow-up showed successful healing without surgery.

On the other hand, surgical management would have involved removal of diseased periapical tissue, and possibly apicectomy, under local anaesthesia in an outpatient facility or under general anaesthesia in an operating theatre. To children and young adults, a surgical procedure would normally be unpleasant and more traumatic than conventional endodontic treatment. Moreover, apicectomy would certainly reduce the available length of a young or immature tooth. This complication would be averted by adopting a conservative procedure that would allow the root canal and apices to heal and attain a mature configuration(10-15). In turn, this would convey a distinct mechanical advantage for the preparation of a postretained jacket crown should it become a clinical necessity. However, for those patients who cannot be relied on to keep long intervals of recall appointments for any reason, surgical management remains a more practical option.

\section{CONCLUSION}

The conservative endodontic procedure described here offers a distinctly more acceptable alternative from both the young patients' and clinicians' point of view. Furthermore, the outcome highlights the need to encourage specialists in related disciplines to work with one another to enhance their knowledge and skills in treatment and appreciate referrals. The practice would help remove barriers that may exist between professions, disciplines or subspecialities and in turn improve the quality of health service delivered to patients.

\section{ACKNOWLEDGEMENTS}

To Professor H.O. Obura, Consultant E.N.T Surgeon, for referring this patient and Tumaini Medical Laboratory for providing the results of bacteriological investigations with utmost accuracy. My sincere gratitude to the patient for his timely appointments and understanding throughout the period of treatment. Finally, to Miss J. K. Ireri for secretarial services.

\section{REFERENCES}

1. Grossman, L.I. Endodontic Practice. 9th ed. pp 67-92 Philadelphia: Lea and Febiger. 1979.

2. O'Brien, J.A. Chronic Periapical Infections, In: Gustav O. Kruger (ed). Textbook of Oral and Maxillofacial Surgery pp208216 St. Louis, Missouri: The C.V. Mosby Company. 1979.

3. Harty, F.J. Endodontics in Clinical Practice pp96-114, Bristol: Wright. 1976.

4. Andreasen J.O. Traumatic injuries of the teeth. 2nd ed. pp 330-335. Copenhagen: Munksgaard. 1981.

5. Rock, W.P., Gordon, P.H., Friend, L.A., and Grundy, M.C. The relationship between trauma and pulp death in incisor teeth. Brit. Dent. J. 1974; 136: 236-239.

6. Kennedy, D.P. Paediatric Operative dentistry. 3rd ed. pp 248-254. Bristol: Wright, 1986.

7. Estrela, C., Pecora, J.D., Souza-Neto, M.D., Estrela, C.R.A., and Bamman, L.L. Effects of vehicles on antimicrobial properites of calcium hydroxide pastes. Braz. Dent. J. 1999; 10:63-72.

8. Heling, I., Bialla-Shenkman, S., Turetzky, A., Horowitz, J., and Sela, J. The outcome of teeth with periapical periodontitis treated with non-surgical endodontic treatment: A computerised morphometric study. Quintessence Int. 2001; 32:397-400.

9. Ashley M. and Harris I. The assessment of the endodontically treated teeth. Dent. update. 2001; 28: 247-252.

10. Holland, R. and Souza, V. Ability of a new calcium hydroxide root canal filling material to induce hard tissue formation. J. endodont. 1985; 11:535-543.

11. Soares I, Goldberg F. Massone E. J. and Soares I.M. Periapical tissue response to two calcium hydroxidecontaining Endodontic sealers J. Endodont. 1990; 16: 166-169.

12. Watanabe, U., Nakagawa, K. and Asai, Y. Tissue changes following human pulp dressing with calcium hydroxide cements. Dentistry in Japan. 1992; 29:41-51.

13. Hashiguchi, I., Yamara, T., Nakano, T., et al. Histological examination of the biocompatibility of calcipex, a new calcium hydroxide containing intracanal dressing, after filling bony defects. Dentistry in Japan. 2001; 37:51-55.

14. Rodd, H.D., Davidson, L.E., Livesey, E. and Cooke, M.E. Survival of intentionally retained permanent incisor roots following crown root fractures in children. Dent. Traumatol. 2002; 18:92-97.

15. Barnett, F. The role of endodontics in the treatment of luxated permanent teeth. Dent. Traumatol. 2002; 18: 47-56. 